\title{
KONDISI STRES DAN STRATEGI KOPING KELUARGA DALAM MENINGKATKAN KEPATUHAN PEMBATASAN CAIRAN KLIEN YANG MENJALANI PROGRAM HEMODIALISIS
}

\section{Stress and family Coping Strategy in Improving Adherence of Fluid Restrictions on Client Undergoing Hemodialysis Program}

\section{Nurul Hidayah*1, Joni Haryanto2, Yanis Kartini3}

\author{
1Magister Student of Faculty of Nursing, Universitas Airlangga, Surabaya \\ ${ }_{2}$ Faculty of Nursing, Universitas Airlangga, Surabaya \\ 3Faculty of Nursing and Midwifery, Universitas Nahdlatul Ulama, Surabaya
}

\section{Riwayat artikel \\ Diajukan: 31 Juli 2019 \\ Diterima: 28 Maret 2020}

\section{Penulis Korespondensi: \\ - Nurul Hidayah \\ - Fakultas keperawatan, Universitas Airlangga noerelhidayah89@gmail com}

\section{Kata Kunci:}

Stres, strategi koping, keluarga, hemodialisis, Family Centered Nursing

\begin{abstract}
Abstrak
Pendahuluan: Pembatasan cairan menjadi masalah utama klien PGK dengan hemodialisis. Kepatuhan terhadap pembatasan cairan dapat ditingkatkan melalui dukungan keluarga, ahli (perawat/ dokter), dan motivasi lingkungan. Dukungan sosial berpengaruh terhadap kepatuhan klien dalam pembatasan cairan. Tujuan penelitian ini menganalisis faktorfaktor yang berhubungan dengan meningkatkan kepatuhan pembatasan cairan klien hemodialisis. Metode: Jenis penelitian obsevasional study dengan desain cross-sectional. Sampel 110 klien hemodialisis dan keluarganya pada Juni 2019 di unit hemodialisa RSUD Kabupaten Jombang. Variabel independen adalah faktor keluarga: pengetahuan; pendapatan; lingkungan; struktur; fungsi dan tugas kesehatan; stress dan strategi koping keluarga. Variabel dependen adalah kepatuhan pembatasan cairan. Pengumpulan data dilakukan dengan kuesioner. Analisis data menggunakan Chi Square. Hasil: Stres dan strategi koping keluarga berhubungan terhadap kepatuhan pembatasan cairan klien PGK yang menjalani program hemodialisis dengan nilai $\mathrm{p}$ value $(\mathrm{p}=0.003$ dan $\mathrm{p}=$ 0.000). Diskusi: efektivitas manajemen stres dan strategi koping keluarga akan mempengaruhi energi dan respons adaptif keluarga dalam menjalankan setiap peran dan fungsi dalam keluarga, semakin baik strategi koping keluarga, semakin baik kemampuan keluarga untuk menurunkan stres akan meningkatkan kesejahteraan dan mengontrol kesehatan mereka.
\end{abstract}

Abstract
Introduction: Fluid restriction is a major problem for CKD clients with hemodialysis. Adherence of fluid restrictions can be increased through family support, experts (nurses / doctors), and environmental motivation. Social support affects adherence in fluid restrictions on client. The purpose of this study was to analyze the effect of family factors in the theory of Family Centered Nursing (FCN) as a source of support for adherence fluid restriction in Chronic Kidney Disease (CKD) client undergoing hemodialysis programs. Method: This type of study is an observational study with a cross-sectional design. A sample of 110 hemodialysis clients and their families in June 2019 in the hemodialysis unit at Jombang District Hospital. Independent variables are family factors: stress and family coping strategies. The dependent variable is the adherence of fluid restriction. Data collection is done by questionnaire. Data analysis using Chi Square. Results: Stress and family coping strategies is associated with increased adherence of fluid restriction on clients undergoing hemodialysis programs with $p$ value ( $p=0.003, p=0,000)$. Discussion: the effectiveness of stress management and family coping strategies will affect the family's energy and adaptive response in carrying out each role and function in the family, the better the family coping 
strategy the better the family's ability to improve their welfare and control their health.

Jurnal Ilmiah Keperawatan (Scientific Journal of Nursing), Vol 6, No 1, Tahun 2020 


\section{PENDAHULUAN}

Penyakit Ginjal Kronik (PGK) menjadimasalah kesehatan utama seluruh dunia mengakibatkan angka morbiditas dan mortalitas tinggi sertabeban sosial dan finansial yang signifikan(Melegy, 2016). Klien PGK tahap End Stage Renal Disease (ESRD) memerlukan terapi pengganti ginjal (Kim \& Kim, 2015) dan hemodialisis adalah terapi paling umum dilakukan oleh klien dengan PGK (Düzalan \& Pakyüz, 2018). Klien dengan hemodialisisharus menjalani adaptasi signifikan terkait pembatasan asupan cairan, diet, ketergantunganobat-obatan juga adaptasi psikososial(Clark, Farrington, \& Chilcot, 2014). Sampai saat ini pembatasan asupan cairan masih menjadi masalah utama pada perawatan klien PGK yang menjalani program hemodialisis (Howren, et al., 2016).

Kabupaten Jombang pada tahun 2013 memiliki rata-rata $12-18$ klien baru yang menjalani hemodialisis setiap bulannya (Pujiani \& Masruroh, 2017) dengan pertumbuhan sebesar $0.016 \%$, ini merupakan prosentase yang tinggi dibandingkan dengan pertumbuhan jumlah klien yang menjalani program hemodialisis di Jawa Timur yaitu 0,012\% (Indonesian Renal Registry, 2015). Hasil studi pendahuluan di RSUD Kabupaten Jombang terdapat masalah kelebihan cairan yang dialami klien hemodialisis sebesar 58\%. Upaya yang dilakukan masih sebatas edukasi perawat dengan media leaflet dirasa masih belum optimal.

Teori Family Centered Nursing (FCN) dari Friedman (2010) yang mengidentifikasi faktor klien dan keluarga sebagai dasar pengkajian keberhasilan melakukan suatu proses keperawatan. Tujuan keperawatan keluarga adalah membantu keluarga ini, adalah untuk mencapai tugas kesehatan keluarga atau meningkatkan kesejahteraan keluarga keposisi yang lebih tinggi (Friedman, Bowden, \& Jones, 2010). Keluarga sebagai sistem interpersonal klien akan sangat penting dan berpengaruh terhadap pencapaian kepatuhan klien.
Menurut penelitian yang menganalisis tema kepatuhan klien hemodialisis terhadap pembatasan cairan sebelumnya, klien berhasil patuh dengan adanya dukungan dari keluarga, ahli (perawat dan dokter), dan motivasi dari pengalaman bersama klien HD (Stevenson, Tong, Gutman, et al., 2018). Stres merupakan perasaan yang menekan yang dialami oleh individu/ keluarga dalam menghadapi permasalahan tertentu (Pujiani \& Masruroh, 2017) sedangkan Koping merupakan cara yang dapat dilakukan individu/ keluarga, dalam menyelesaikan masalah yang terjadi, menyesuaikan diri dengan keinginan yang akan dicapai, dan respons terhadap situasi yang menjadi ancaman bagi diri individu (Agustina, 2013). Keseimbangan dalam pengelolaan kedua faktor ini dimungkinkan akan memperbaiki kepatuhan dalam usahausaha meningkatkan kesehatan. Tujuan penelitian ini adalah untuk menganalisis pengaruh faktor stress dan strategi koping keluarga terhadap kepatuhan pembatasan asupan cairan pada klien penyakit ginjal kronik (PGK) yang menjalani program hemodialisis di RSUD Kabupaten Jombang.

\section{METODE}

Penelitian ini menggunakan desain obsevasional study dengan pendekatan cross sectional.Pengumpulan data dilakukan secara kuantatif dengan wawancara dan menggunakan kuesioner yang diisi responden baik klien maupun keluarga di unit hemodialisis RSUD Kabupaten Jombang. Populasi yaitu klien hemodialisis dan keluarga yang mengantar klien untuk hemodialisis di unit hemodialisis RSUD Kabupaten Jombang pada bulan Juni 2019. Sampel dalam penelitian ini diambil dari populasi dengan kriteria inklusi dan eksklusi, yaitu:

1. Kriteria Inklusi Responden Klien

1) Berusia 18 - 65 tahun

2) Dapat memahami bahasa Indonesia 
3) Klien menjalani hemodialisis $\geq 3$ bulan

2. Kriteria inklusi responden keluarga dalam penelitian ini:

1) Berusia 18 - 65 tahun

2) Dapat memahami bahasa Indonesia

3) Memiliki hubungan kerabat/ keluarga dengan klien

4) Tinggal serumah dengan klien dirumah

3. Kriteria eksklusi responden klien dalam penelitian ini:

1) Klien dengan gangguan penglihatan, pendengaran dan kejiwaan

2) Klien dengan komplikasi penyulit (gangguan kardiovaskuler, dsb)

4. Kriteria eksklusi responden keluarga dalam penelitian ini:

1) Klien dengan gangguan penglihatan, pendengaran dan kejiwaan

\section{HASIL}

Berdasarkan tabel 1.1 menunjukkan bahwa dari 110 responden keluarga hampir sebagian responden keluarga merasa dalam keadaan stres (46.4\%). Berdasarkan tabel 1.2 menunjukkan bahwa dari 110 responden keluarga lebih dari sebagian menunjukkan strategi koping keluarga yang kurang (59.1\%). Berdasarkan tabel 1.3 menunjukkan bahwa dari 110 responden klien lebih dari sebagian menunjukkan kepatuhan pembatasan asupan cairan yang kurang (57.3\%). Berdasarkan tabel 1.4 menunjukkan bahwa kepatuhan pembatasan cairan klien dalam kategori baik lebih dari sebagian memiliki keluarga dengan kondisi keluarga
1) Baru pertama kali mengantar klien untuk HD

Teknik sampel menggunakan probability sampling dengan simple random sampling.Besar sampel didapatkan melalui rumus besar sampel. Besar sampel dalam penelitian ini adalah 110 responden klien dan 110 responden keluarga. Variabel independen dalam penelitian ini adalah faktor keluarga, terdiri dari: stress dan strategi koping keluarga. Variabel dependen adalah kepatuhan pembatasan asupan cairan. Analisis statistik menggunakan Chi Square. Persetujuan etik dikeluarkan oleh Komite Etik Penelitian Kesehatan (KEPK) RSUD Kabupaten Jombang dengan Nomor: 42/KEPK/V/2019.

tidak stress (52,5\%), sebaliknya yang memiliki kepatuhan pembatasan asupan cairan kurang, lebih dari sebagian mengalami stres $(60,8 \%)$.Stress keluarga dengan kepatuhan pembatasan cairan memiliki hubungan signifikan dengan $\mathrm{p}=0.003$. Berdasarkan tabel 1.5 menunjukkan bahwa kepatuhan pembatasan cairan klien dalam kategori baik sebagian besar memiliki strategi keluarga baik pula $(78,9,5 \%)$, sebaliknya yang memiliki kepatuhan pembatasan asupan cairan kurang, lebih dari sebagian keluarganya mengalami stres $(78,5 \%)$. Strategi koping keluarga dengan kepatuhan pembatasan cairan memiliki hubungan signifikan dengan $\mathrm{p}=0.003$. 
Tabel 1.1 Distribusi Stres Keluarga, Juni 2019

\begin{tabular}{llcccc}
\hline & Jumlah & $\begin{array}{c}\text { Prosentase } \\
(\%)\end{array}$ & Persen Valid & Persen Kumulatif \\
\hline \multirow{2}{*}{ Valid } & tidak stres & 40 & 36.4 & 36.4 & 36.4 \\
\cline { 2 - 6 } & cukup stres & 19 & 17.3 & 17.3 & 53.6 \\
\cline { 2 - 6 } & stres & 51 & 46.4 & 46.4 & 100.0 \\
\cline { 2 - 6 } & Total & 110 & 100.0 & 100.0 & \\
\hline
\end{tabular}

Tabel 1.2 Distribusi Strategi Koping Keluarga, Juni 2019

\begin{tabular}{llcccc}
\hline \multirow{2}{*}{ Valid } & Jumlah & $\begin{array}{c}\text { Prosentase } \\
(\%)\end{array}$ & Persen Valid & Persen Kumulatif \\
\cline { 2 - 6 } & baik & 38 & 34.5 & 34.5 & 34.5 \\
\cline { 2 - 6 } & cukup & 7 & 6.4 & 6.4 & 40.9 \\
\cline { 2 - 6 } & kurang & 65 & 59.1 & 59.1 & 100.0 \\
\cline { 2 - 6 } & Total & 110 & 100.0 & 100.0 & \\
\hline
\end{tabular}

Tabel 1.3 Distribusi Kepatuhan Pembatasan Asupan Cairan, Juni 2019

\begin{tabular}{llcccc}
\hline \multirow{2}{*}{ Valid } & Jumlah & $\begin{array}{c}\text { Prosentase } \\
(\%)\end{array}$ & Persen Valid & Persen Kumulatif \\
\cline { 2 - 6 } & baik & 38 & 34.5 & 34.5 & 34.5 \\
\cline { 2 - 6 } & cukup & 9 & 8.2 & 8.2 & 42.7 \\
\cline { 2 - 6 } & kurang & 63 & 57.3 & 57.3 & 100.0 \\
\cline { 2 - 6 } & Total & 110 & 100.0 & 100.0 & \\
\hline
\end{tabular}

Tabel 1.4 Hubungan antara Stres Keluarga dengan Kepatuhan pembatasan asupan cairan klien PGK yang menjalani Program Hemodialisis 


\begin{tabular}{|c|c|c|c|c|c|}
\hline \multirow{2}{*}{ Stress keluarga } & \multicolumn{3}{|c|}{ Kepatuhan Pembatasan Cairan } & \multirow{2}{*}{ Total } & \multirow{2}{*}{$\mathbf{p}$} \\
\hline & baik & cukup & kurang & & \\
\hline \multirow[t]{2}{*}{ tidak stres } & 21 & 1 & 18 & 40 & \multirow{8}{*}{0.03} \\
\hline & $52.5 \%$ & $2.5 \%$ & $45.0 \%$ & $100.0 \%$ & \\
\hline \multirow[t]{2}{*}{ cukup stres } & 1 & 4 & 14 & 19 & \\
\hline & $5.3 \%$ & $21.1 \%$ & $73.7 \%$ & $100.0 \%$ & \\
\hline \multirow[t]{2}{*}{ stres } & 16 & 4 & 31 & 51 & \\
\hline & $31.4 \%$ & $7.8 \%$ & $60.8 \%$ & $100.0 \%$ & \\
\hline \multirow{2}{*}{ Total } & 38 & 9 & 63 & 110 & \\
\hline & $34.5 \%$ & $8.2 \%$ & $57.3 \%$ & $100.0 \%$ & \\
\hline
\end{tabular}

Tabel 1.5 Hubungan antara Strategi Koping Keluarga dengan Kepatuhan pembatasan asupan cairan klien PGK yang menjalani Program Hemodialisis

\begin{tabular}{|c|c|c|c|c|c|}
\hline \multirow{2}{*}{ strategi koping keluaerga } & \multicolumn{3}{|c|}{ Kepatuhan pembatasan cairan } & \multirow{2}{*}{ Total } & \multirow{2}{*}{$\mathbf{p}$} \\
\hline & Baik & Cukup & Kurang & & \\
\hline \multirow{2}{*}{ baik } & 30 & 0 & 8 & 38 & \multirow{8}{*}{0.000} \\
\hline & $78.9 \%$ & $.0 \%$ & $21.1 \%$ & $100.0 \%$ & \\
\hline \multirow{2}{*}{ cukup } & 0 & 3 & 4 & 7 & \\
\hline & $.0 \%$ & $42.9 \%$ & $57.1 \%$ & $100.0 \%$ & \\
\hline \multirow{2}{*}{ kurang } & 8 & 6 & 51 & 65 & \\
\hline & $12.3 \%$ & $9.2 \%$ & $78.5 \%$ & $100.0 \%$ & \\
\hline Count & 38 & 9 & 63 & 110 & \\
\hline$\%$ within strategikopingkeluaerga & $34.5 \%$ & $8.2 \%$ & $57.3 \%$ & $100.0 \%$ & \\
\hline
\end{tabular}

\section{PEMBAHASAN}

Peningkatan asupan cairan dapat menyebabkan overload cairan pada klien dengan hemodialisis mengakibatkan peningkatan beban jantung dan dapat secara langsung menyebabkan hipertrovi ventrikel kiri (Suwitra, 2014). Pembatasan asupan cairan pada kondisi demikian sangat perlu dilakukan, hal ini bertujuan untuk mencegah terjadinya edema dan komplikasi kardiovaskuler yang memperburuk kondisi dan menurunkan kualitas hidup klien hemodialisis. kepatuhan pembatasan asupan cairan dapat dinilai dari penambahan berat badan antara dua proses hemodialisis/ Interdialytic Weight Gain (IDWG) dan diukur sebagai dasar untuk mengetahui jumlah cairan yang masuk selama periode interdialitik (Jaeger \& Mehta, 2009).

Kepatuhandalam konteks kesehatan (compliance atau adherence) merupakan ukuran sejauh mana klien mengikuti instruksi atau saran medis(Sabate, 2001). Kepatuhan merupakan fenomena multidimensi yang ditentukan oleh limadimensi yang saling terkait, yaitufaktor klien, faktor terapi, faktor sistem kesehatan, faktor lingkungan dan faktorsosial ekonomi.Semuafaktor adalahfaktor penting dalam mempengaruhi kepatuhan sehingga tidak ada pengaruh yang lebih kuat dari faktor lainnya (WHO, 2015). Dalam konteks terapi, kepatuhan klien dalam pembatasan asupan cairan merupakan derajat kesesuaian antara intake cairan yang 
diminum dengan output urin sebagaimana telah dianjurkan.

Tori Family Centered Nursing $(F C N)$ yang mengidentifikasi pengkajian faktor keluarga dan faktor klien sebagai dasar keberhasilan melakukan suatu proses keperawatan, menyebutkan bahwa social budaya (pengetahuan, pendapatan), lingkungan, struktur, fungsi dan tugas kesehatan, stress serta strategi koping keluarga berpengaruh dalam keberhasilan sebuah proses keperawatan.

Hasil penelitian menunjukkan bahwa pengetahuan keluarga signifikan secara statistic dalam mempengaruhi kepatuhan pembatasan cairan.

Stress dan strategi koping keluarga signifikan secara statistic dalam mempengaruhi kepatuhan pembatasan cairan pada klien PGK yang menjalani hemodialisis. Klien kurang patuh terhadap pembatasan cairan adalah yang memiliki kategori stress keluarga kurang dengan persentase lebih dari sebagian $(60,8 \%)$. Stres merupakan perasaan yang menekan yang dialami oleh individu/ keluarga dalam menghadapi permasalahan tertentu (Pujiani \& Masruroh, 2017). Keluarga yang mengalami ketegangan dalam penyediaan pelayanan memiliki efek kesehatan fisik dan psikologi (strres) (Agustina, 2013). keluarga yang merawat anggota keluarganya yang menderita GGK yang menjalani hemodialisis juga terkena dampak yang cukup menyulitkan Dampak yang dirasakan keluarga dalam merawat pasien GGK yang menjalani hemodialisis adalah pada emosi, sosial, fisik, dan keuangan. Stres yang berkepanjangan ini akan mengganggu individu dalam menyelesaikan tugas perkembangan (Priyoto, 2014). Stress yang dirasakan kuarga akan mempengaruhi energy dan respon adaptif keluarga dalam melaksanakan masing-masing peran dan fungsi dalam keluarga, sehingga keluarga kurang mampu dalam memberikan dukungan perawatan pada klien. Oleh karena itu upaya untuk edukasi dalam mengelola/ manajemen stress pada keluarga perlu ditingkatkan.

Pada variabel strategi koping keluarga, klien kurang patuh terhadap pembatasan cairan adalah yang memiliki strategi koping keluarga kategori kurang dengan persentase sebagian besar $(78,5 \%)$. Koping merupakan cara yang dapat dilakukan individu/ keluarga, dalam menyelesaikan masalah yang terjadi, menyesuaikan diri dengan keinginan yang akan dicapai, dan respons terhadap situasi yang menjadi ancaman bagi diri individu (Agustina, 2013). Keluarga dengan strategi koping yang efektif akan lebih tenang dan dapat memutuskan upaya-upaya penyelesaian masalah lebih rasional dibandingkan dengan yang memiliki strategi koping tidak efektif. Hal ini juga sejalan dengan pendapat yang dikemukakan (Connor, Jardine, \& Millar, 2008) bahwa strategi koping yang berfokus pada manajemen stress/ emosi menentukan keberhasilan terhadap hasil yang ingin dicapai (kepatuhan terhadap pembatasan cairan). Peningkatan edukasi pada keluarga terutama tentang informasi kondisi terkait penyakit anggota keluarga diharapkan akan menigkatkan dukungan pada klien dan juga kekayaan pengetahuan keluarga sebagai bekal dalam menghadapi segala situasi berkenaan dengan merawat anggota keluarga yang menjalani hemodialisis.

\section{KESIMPULAN DAN SARAN Kesimpulan}

Stres keluarga dan strategi koping keluarga merupakan beberapa faktor dari keluarga yang berpengaruh terhadap kepatuhan pembatasan asupan cairan klien PGK yang menjalani program hemodialisis.

Keefektifan manajemen stres dan strategi koping keluarga menghadapi segala permasalahan karena merawat anggota keluarga yang sakit dapat meningkatkan kepatuhan pembatasan cairan dan menurunkan resiko potensial dari hasil yang merugikan terkait penyakit. 


\section{Saran}

Pegadaan program peningkatan pengetahuan dan motivasi keluarga, serta manajemen stress dan strategi koping keluarga melalui edukasi yang dilakukan oleh petugas kesehatan (perawat), dan hemodialisis peer group sebagai sebagai lingkungan interpersonal klien dan motivator eksternal klien sangat diperlukan untuk meningkatkan kepatuhan pembatasan asupan cairan klien, selain itu peningkatan pemantauan kepatuhan pembatasan cairan dari perawat dan keluarga diharapkan akan semakin meningkatkan kualitas hidup klien yang menjalani program hemodialisis.

\section{DAFTAR PUSTAKA}

Boyd, A., Yang, C. T., Estell, K., MS, C., Gerald, L. B., Dransfield, M., ... Schwiebert, L. M. (2012). Feasibility of exercising adults with asthma: a randomized pilot study. Allergy, Asthma \& Clinical Immunology, 8(1), 13. https://doi.org/10.1186/1710-1492-8-13

Clark, S., Farrington, K., \& Chilcot, J. (2014). Nonadherence in dialysis patients: Prevalence, measurement, outcome, and psychological determinants. Seminars in Dialysis, 27(1), 42-49. https://doi.org/10.1111/sdi.12159

Düzalan, Ö. B., \& Pakyüz, S. C. (2018). Educational interventions for improved diet and fluid management in haemodialysis patients : An interventional study. JPMA, 68, 532537.

França-Pinto, A., Mendes, F. A. R., de Carvalho-Pinto, R. M., Agondi, R. C., Cukier, A., Stelmach, R., ... Carvalho, C. R. F. (2015). Aerobic training decreases bronchial hyperresponsiveness and systemic inflammation in patients with moderate or severe asthma: a randomised controlled trial. Thorax, 70(8), 732-739. https://doi.org/10.1136/thoraxjnl-2014206070

Friedman, M. M., Bowden, V. R., \& Jones, E. G. (2010). Buku Ajar Keperawatan Keluarga: Riset, Teori dan Praktik. Jakarta: EGC.

Ghebre, M. A., Bafadhel, M., Desai, D., Cohen, S. E., Newbold, P., Rapley, L., ... Brightling, C. E. (2015). Biological clustering supports both "dutch" and "british" hypotheses of asthma and chronic obstructive pulmonary disease. Journal of Allergy and Clinical Immunology, 135(1), 6372.e10.

https://doi.org/10.1016/j.jaci.2014.06.0 35

GINA. (2018). Global Strategy for Asthma Management and Prevention.

Grzela, K., Zagorska, W., Krejner, A., Litwiniuk, M., Zawadzka-Krajewska, A., Banaszkiewicz, A., ... Grzela, T. (2015). Prolonged Treatment with Inhaled Corticosteroids does not Normalize High Activity of Matrix Metalloproteinase-9 in Exhaled Breath Condensates of Children with Asthma. Archivum Immunologiae et Therapiae Experimentalis, 63(3), 231-237. https://doi.org/10.1007/s00005-0150328-z

Hall, C., Nici, L., Sood, S., Zuwallack, R., Castro, M., \& Louis, S. (2017). Nonpharmacologic Therapy for Severe Persistent Asthma. The Journal of Allergy and Clinical Immunology: In Practice, 5(4), 928-935. https://doi.org/10.1016/j.jaip.2017.04.0 30

Howren, M. B., Kellerman, Q. D., Hillis, S. L., Cvengros, J., Lawton, W., \& Christensen, A. J. (2016). Effect of a Behavioral Self-Regulation Intervention on Patient Adherence to Fluid-Intake Restrictions in Hemodialysis: a Randomized Controlled Trial. Ann. 
Behav. Med., 167-176. https://doi.org/10.1007/s12160-0159741-0

Indonesian Renal Registry. (2015). 8th Report Of Indonesian Renal Registry. Program Indonesia Renal Registry, 145. https://doi.org/10.2215/CJN.02370316

Kim, Y., \& Kim, M. (2015). The Experience of Fluid Management in Hemodialysis Patients. Korean Academy of Nursing Science, 45(5), 773-782.

Melegy, Z. \& K. (2016). Effect of family centered empowerment model on hemodialysis patients and their caregivers, 6(11), 119-132. https://doi.org/10.5430/jnep.v6n11p119 Mohamed, Z., Riad, N. M., \& Ahmed, F. H. (2013). Effect of Buteyko breathing technique on patients with bronchial asthma. Egyptian Journal of Chest Diseases and Tuberculosis, 61(4), 235241. https://doi.org/10.1016/j.ejcdt.2012.08. 006

Pakhale, S., Luks, V., Burkett, A., \& Turner, L. (2013). Effect of physical training on airway inflammation in bronchial asthma: A systematic review. $B M C$ Pulmonary Medicine, 13(1), 1. https://doi.org/10.1186/1471-2466-1338

PDPI. (2012). Pedoman Praktis Diagnosis dan Penatalaksanaan di Indonesia. Jakarta: Departemen Kesehatan Republik Indonesia.

Pujiani, \& Masruroh. (2017). Program Psikoedukasi Terhadap Peningkatan Kualitas Hidup Pasien Gagal Ginjal Kronik, 1(1), 47-56.

Sahat, C. S., Irawaty, D., \& Hastono, S. P. (2011). Peningkatan kekuatan otot pernapasan dan fungsi paru melalui senam asma pada pasien asma. Jurnal Keperawatan Indonesia, 14, 101-106.

Stevenson, J., Tong, A., Gutman, T.,
Campbell, K. L., Craig, J. C., Brown, M. A., \& Lee, V. W. (2018). Experiences and Perspectives of Dietary Management Among Patients on Hemodialysis: An Interview Study. Journal of Renal Nutrition, 1-11. https://doi.org/10.1053/j.jrn.2018.02.00 5

Victoria, A., Evangelos, F., \& Sofia, Z. (2015). Family support, social and demographic correlations of nonadherence among haemodialysis patients, (August 2017). https://doi.org/10.11648/j.ajns.s.201504 0201.21 
Jurnal Ilmiah Keperawatan (Scientific Journal of Nursing), Vol 6, No 1, Tahun 2020

(Hidayah, N, et al, 2020) 